\title{
Erratum to: Computational Modeling of Arc-Slag Interaction in DC Furnaces
}

\author{
QUINN G. REYNOLDS ${ }^{1,2}$ \\ 1.-Pyrometallurgy Division, Mintek, Rabdburg 2194, South Africa. 2.—e-mail: quinnr@mintek.co.za
}

\section{Erratum to: JOM}

\section{DOI: $10.1007 / \mathbf{s 1 1 8 3 7 - 0 1 6 - 2 1 6 6 - 9}$}

In the published version of the paper, Equations 1-5 (the governing equations of plasma arc formation and evolution) were reproduced with incorrect format and mathematical operators. The correct versions are shown below and should be substituted where appropriate.

$$
\begin{gathered}
\frac{\partial(\rho \mathbf{u})}{\partial t}+\nabla \cdot(\rho \mathbf{u u})+\nabla P= \\
+\mathbf{j} \times \nabla \times \mathbf{A}-\rho \mathbf{g}-\gamma \nabla\left(\frac{\nabla \alpha}{|\nabla \alpha|}\right) \nabla \alpha \\
\frac{\partial \rho}{\partial t}+\nabla \cdot(\rho \mathbf{u})=0
\end{gathered}
$$

$$
\begin{gathered}
\frac{\partial \alpha}{\partial t}+\nabla \cdot(\alpha \mathbf{u})=0 \\
\frac{\partial\left(\rho C_{P} T\right)}{\partial t}+\nabla \cdot\left(\rho C_{P} \mathbf{u} T\right)= \\
\nabla \cdot\left(k \nabla T+\frac{5 k_{B} \mathbf{j}}{2 e} T\right) \\
+\frac{\mathbf{j} \cdot \mathbf{j}}{\sigma}-Q_{R}
\end{gathered}
$$

The online version of the original article can be found under doi:10.1007/ s11837-016-2166-9. 